\title{
Home-based physiotherapy programmes for individuals with neurological diseases: systematic review
}

\author{
Programas de fisioterapia Home-based para indivíduos \\ com doenças neurológicas: revisão sistemática
}

\section{Programas de fisioterapia Home-based para individuos con enfermedades neurológicas: revisión sistemática}

\section{Paulo Roberto Fonseca Junior ${ }^{[1]}{ }^{[a, b]}$, Paola Pinto Souza ${ }^{[1]}{ }^{[a]}$, Kelly Kuguio Maurino dos Reis (i) [a], Eduardo Filoni $[$ [c] [c]}

[a] Universidade Guarulhos (UnG), Guarulhos, SP, Brazil

[b] Faculdade de Ciências Médicas Santa Casa de São Paulo (FCMSCSP), São Paulo, SP, Brazil

[c] Universidade Mogi das Cruzes (UMC), Mogi das Cruzes, SP, Brazil

\section{Abstract}

Introduction: Home-based programmes have received increasing attention in rehabilitation, providing an opportunity to continue aspects of therapy, benefiting the retention of established intervention effects. objective: To describe the available home-based physiotherapy programmes in neurorehabilitation for people with neurological diseases. Method: MEDLINE, EMBASE, Cochrane Library, OTseeker and PEDro were searched, no restrictions regarding the date of publication or language restrictions for randomized controlled clinical trial. The quality of the selected studies using the PEDro scale and the Cochrane Collaboration's tool

* PRFJ: MS, e-mail: paulofonseca28@gmail.com PPS: BS, e-mail: paola.psousa2014@gmail.com KKMR: BS, e-mail: kelly_kuguio@yahoo.com.br EF: PhD, e-mail: edufiloni@hotmail.com 
for assessing the risk of bias. Results: Fifteen articles met the eligibility criteria and quality assessment and were selected for the present systematic review. The findings supports the positive impact of home-based intervention, finding evidence in the changes in activity level, improvement in the control and muscle strength, balance and walking in patients with neurological conditions who perform rehabilitation program at home, with a good adherence of participants in total. Conclusion: Models of rehabilitative such as home-based programmes can be an alternative efficient method to deliver rehabilitation, showing to be beneficial in improving different aspects of activities, and participation.

Keywords: Nervous System Diseases. Neurology. Home Care Services. Rehabilitation. Physical Therapy Specialty.

\section{Resumo}

Introdução: Programas home-based têm recebido atenção crescente na reabilitação, proporcionando uma oportunidade para continuar os aspectos da terapia, beneficiando a retenção de efeitos de intervenção estabelecidos. Objetivo: Descrever os programas de fisioterapia home-based disponíveis na neurorreabilitação para pessoas com doenças neurológicas. Método: MEDLINE, EMBASE, Biblioteca Cochrane, OTseeker e PEDro foram pesquisados, sem restrições quanto à data de publicação ou restrições de idioma para ensaios clínicos randomizados controlados. A qualidade dos estudos selecionados usando a escala PEDro e a ferramenta Cochrane Collaboration para avaliar o risco de viés. Resultados: Quinze artigos preencheram os critérios de elegibilidade e avaliação de qualidade e foram selecionados para a presente revisão sistemática. Evidências foram encontradas sobre mudanças no nível de atividade, melhora no controle e força muscular, equilíbrio e deambulação em pacientes com condições neurológicas que realizam um programa de reabilitação homebased, com boa adesão dos participantes no total. Conclusão: Os modelos de reabilitação, como os programas home-based, podem ser um método eficiente alternativo para promover a reabilitação, mostrando-se benéficos na melhoria dos diferentes aspectos das atividades e na participação.

Palavras-chave: Doenças do Sistema Nervoso. Neurologia. Serviços de Assistência Domiciliar. Reabilitação. Fisioterapia.

\section{Resumen}

Introducción: Los programas home-based han recibido una atención creciente en la rehabilitación, proporcionando una oportunidad para continuar los aspectos de la terapia, beneficiando la retención de efectos de intervención establecidos. Objetivo: Describir los programas de fisioterapia Home-Based disponibles en la neurorreabilitación para personas con enfermedades neurológicas. Método: MEDLINE, EMBASE, Biblioteca Cochrane, OTseeker y PEDro fueron investigados, sin restricciones en cuanto a la fecha de publicación o restricciones de idioma para ensayos clínicos randomizados controlados. La calidad de los estudios seleccionados mediante la escala PEDRO y la herramienta Cochrane Collaboration para evaluar el riesgo de sesgo. Resultados: Quince artículos cumplieron los criterios de elegibilidad y evaluación de calidad y fueron seleccionados para la presente revisión sistemática. Se encontraron evidencias sobre cambios en el nivel de actividad, mejora en el control y fuerza muscular, equilibrio y deambulación en pacientes con condiciones neurológicas que realizan un programa de rehabilitación Home-Based, con buena adhesión de los participantes en el total. Conclusión: Los modelos de rehabilitación, como los programas Home-Based, pueden ser un método eficiente alternativo para promover la rehabilitación, mostrándose beneficiosos en la mejora de los diferentes aspectos de las actividades y en la participación.

Palabras clave: Enfermedades del Sistema Nervioso. Neurología. Servicios de Atención Domiciliaria. Rehabilitación. Fisioterapia. 


\section{Introduction}

Neurorehabilitation research has progressed substantially over recent decades. Physical therapy (PT) for neurological patients is a comprehensive process that intends to teach, guide, and promote brain plasticity, thus preserving brain, muscle, and neuromuscular function, being critical to health and quality of life [1-3]. Adherence with treatment is an important factor which can influence the outcome of that treatment. Adherent patients may have better treatment outcomes than nonadherent patients. Poor adherence to treatment has been identified across many healthcare disciplines including physiotherapy, having implications on treatment cost and effectiveness. Within physiotherapy, the concept of adherence is multi-dimensional and could relate to attendance at appointments, following advice, undertaking prescribed exercises, frequency of undertaking prescribed exercise, correct performance of exercises or doing more or less than advised [4-6].

In recent years, home-based programmes have received increasing attention in rehabilitation. These programmes are a useful addition to physiotherapy for a number of reasons. Homebased programmes provide a unique opportunity to continue aspects of therapy, either in between centre-based sessions or after centre-based therapy has ended, benefiting the retention of established intervention effects [7, 8]. They also increase parental or caregivers involvement and empowerment, contributing to parents and health professionals to learn from each other and share each other's perspectives on the rehabilitation. The home-based programmes is considered costeffective and may be the preferred or even the only feasible option in specific contexts, for example, in cases where long distances need to be travelled from the patient's home to the institution [9-11].

The information and communication technology (ICT), such as telerehabilitation (TR), which is transmitted by phone or video, represent an alternative method to deliver therapy in a setting convenient to the patient, such as their home, by minimizing the barriers of distance, time, cost and health care system load [12-14]. However, In the aspect of rehabilitation method, the overall rehabilitation scheme does not integrated TR devices (such as audiovideo conference, use of the internet) and concrete rehabilitation exercises (for example, electrostimulation) together [15-17]. Moreover, in some reviews, the effects of TR were of low level of evidence [12, 15-19]. The lack of convenience is an important barrier to consumer use of interactive health ICT. Patients are less likely to use systems requiring access to equipment or technology that did not fit seamlessly into their normal daily routines. Technical issues often prevented consistent use of health ICT systems, especially among studies conducted on early system prototypes $[19,20]$.

The major aim of this review is to describe the currently available home-based physiotherapy programmes in neurorehabilitation for people with neurological diseases and to introduce the main rehabilitation approaches, their effects and adherence.

\section{Methods}

Protocol and registration

The PRISMA indication (preferential report items for Systematic Analyzes and Meta-analyzes) for conducting reviews of intervention studies was followed [21, 22]. This systematic review of the literature was also recorded in the PROSPERO database (CRD42018093687).

\section{Sources of data and search strategy}

We searched the following databases: MEDLINE (by PubMed), EMBASE, Cochrane Library, OTseeker and PEDro. The articles were searched using the terminology registered in the Medical Subject Headings of the U.S. National Library of Medicine (Mesh). The following terms were used for the literature search: 'Nervous System Diseases', 'Home Care Services', 'Physical Therapy Modalities'. Specifically, papers that were included in this review were required to have the term ('Nervous System Diseases' OR 'neurological disorder' OR 'neurological pathology' OR 'stroke' OR 'CNS infection' OR 'Parkinson's disease' OR 'essential tremor' OR 'epilepsy' OR 'head injury' OR 'multiple sclerosis' OR 'primary brain tumors' OR 'traumatic brain injury' OR 'Huntington's disease' OR 'cerebellar ataxia' OR 'spina bifida' OR 'cerebral palsy' OR 'muscular dystrophies' OR 'dystonia',) 
AND ('Home Care Services' OR 'Home' OR 'in-home' OR 'home-based' OR 'self care' OR 'residence' OR 'domiciliary') AND ('Physical Therapy Modalities' OR 'exercise' OR 'therapy' OR 'therapies' OR 'program' OR 'train' OR 'physiotherapy') located within the title and/or abstract. In addition to the systematic electronic database search, a targeted search of the bibliographies of relevant articles was also performed to identify any additional studies for inclusion.

\section{Study selection}

An initial analysis was performed based on the title and abstract. Titles and abstracts were displayed and selected by two independent researchers to identify the relevant studies. When the title and abstract were unclear, the full text was read. The full texts of articles considered possibly relevant were analyzed to determine whether the articles met the eligibility criteria. In cases of divergence of opinion or doubts about the relevance of article, a third researcher analyzed the texts in question to reach a consensus.

\section{Eligibility criteria}

The following were the inclusion criteria: randomized controlled clinical trial, no restrictions regarding the date of publication or language restrictions, involving subjects diagnosed with any neurological disease, intervention with home-base physiotherapy program based on a motor recovery program. The exclusion criteria was: Pilot study; protocol study; cross-over study; subjects without neurological diseases; clinical trials that do not have a control group; studies based only on cognitive function interventions; interventions based on the use of telerehabilitation.

\section{Quality assessment}

The pre-selected articles were evaluated and scored for methodological quality using the PEDro scale [23]. The classification of the selected studies was performed by two independent researchers blinded to the objectives of the present review. In cases of a divergence of opinion, a third researcher made the decision regarding the score. For inclusion in the present review, all articles needed to achieve a score of 6 points or higher on the PEDro scale.

We conducted a sensitivity analysis through the Cochrane Collaboration tool for bias risk assessment of randomized clinical trials [24], to investigate the robustness of the results to each of the 'Risk of bias' components by including only studies that were at low risk of bias for the most part. We used this information to guide our judgements on the quality of the evidence together with the PEDro quality assessment.

\section{Results}

Seven hundred and ninety-eight articles were retrieved from the databases searched. After the analysis of the titles, abstract and complete texts and the quality assessment using the PEDro scale (Table 1), only fifteen articles met the eligibility criteria and achieved a quality score of 6 points or higher. Figure 1 displays the flowchart of the selection process.

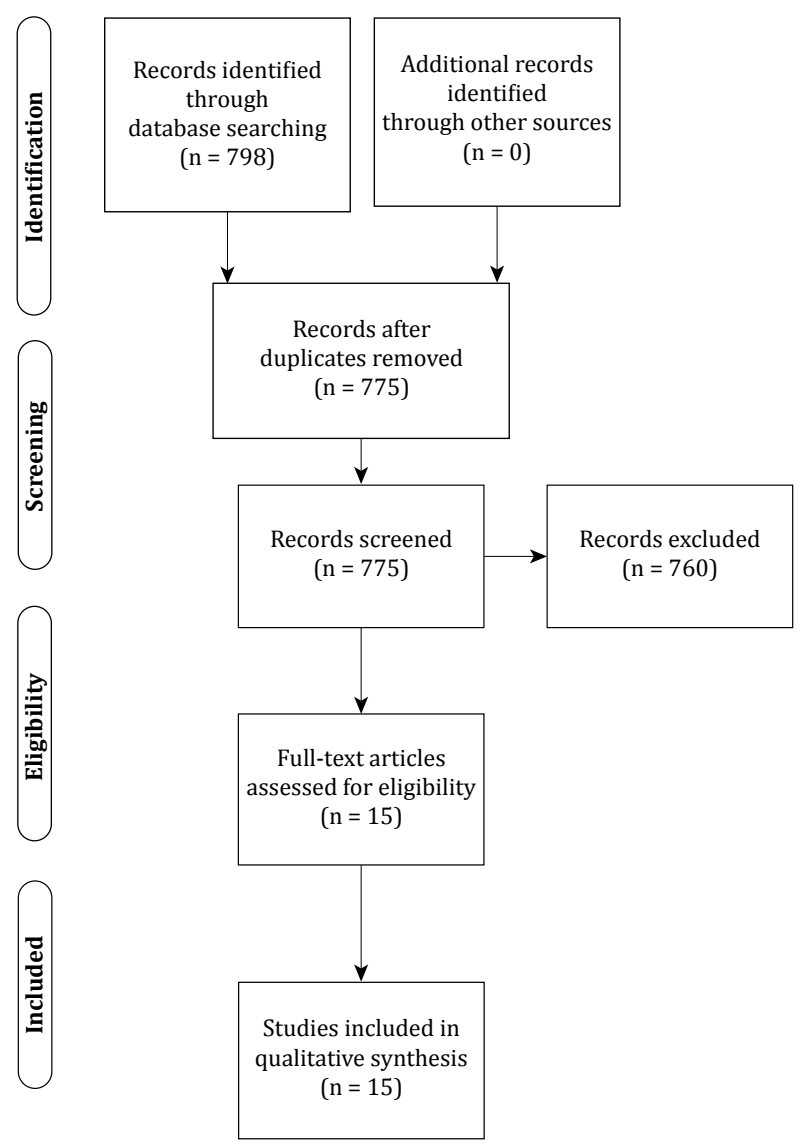

Figure 1-Overview of article selection process. 


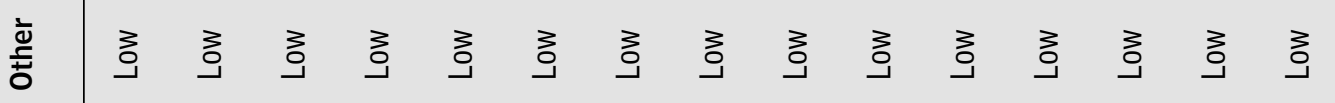

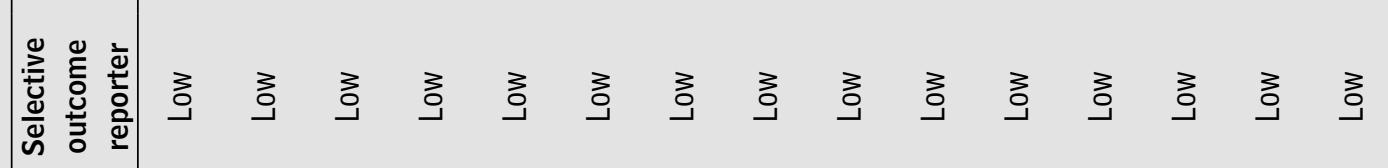

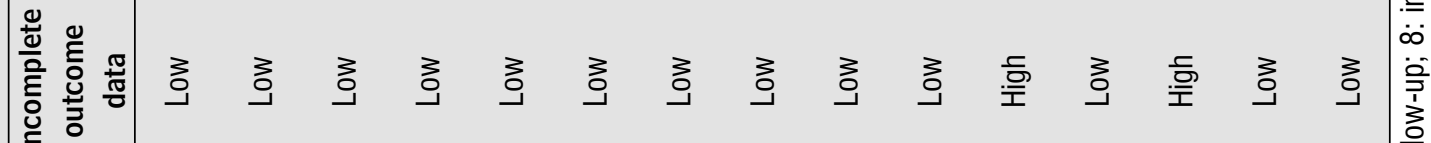

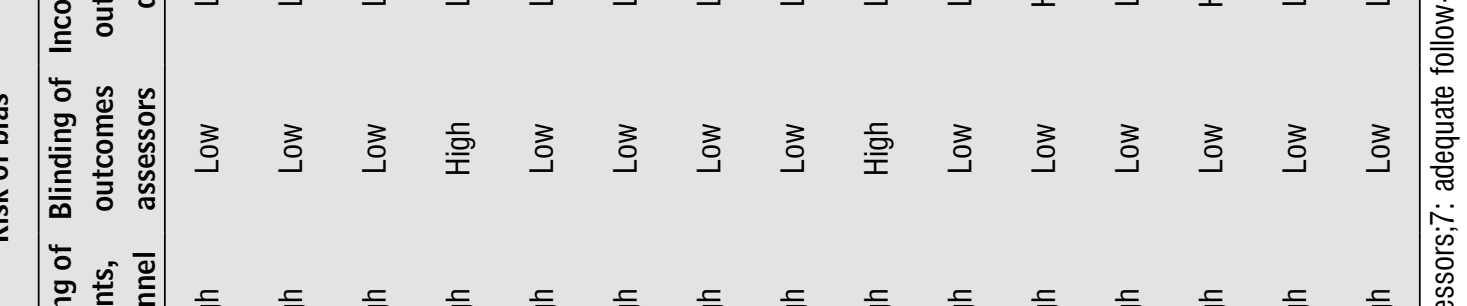

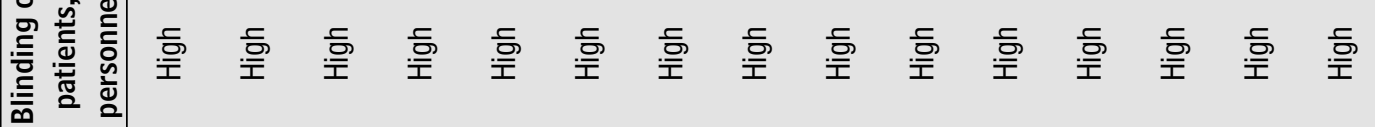
咅

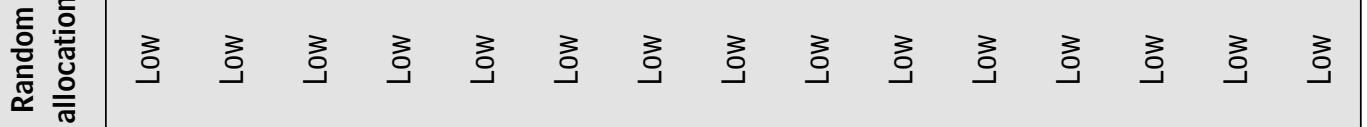

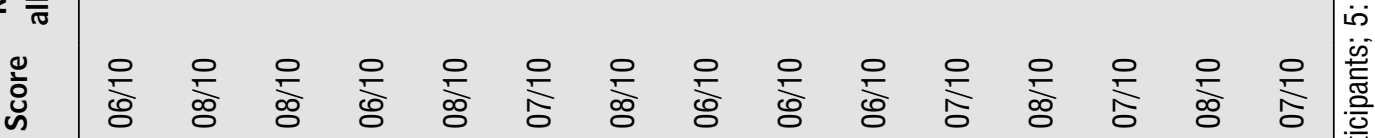


Methodological quality

All fifteen studies included were randomized controlled trials [25-39] and were randomized in a blinded manner. Following the appraisal of methodological quality PEDro and Cochrane Collaboration tool, all studies performed well in terms of internal validity (randomization) as well as the results and quality of reporting (e.g., incomplete outcomes, selective outcome reporting and other biases). Although the controlled and randomized trials included in this review are of good methodological quality (mean PEDro score was 7.0) and are currently considered the gold standard in evidence-based medicine, the subjects and therapists were not blinded in any included study. The blinding of subjects and therapists is difficult in studies that involve interventional or surgical procedures [40].

\section{Home-based intervention characteristics}

Detailed information about the home-based interventions evaluated in the included studies is presented in Table 2 . The interventions used in the included studies varied and generally consisted of the use of a low-cost home rehabilitation program based on functional tasks or rehabilitation exercises that required balance and resistance exercises. All studies were conducted in patients' homes, and the patients receive information and instruction about the programme of exercises and activities to be carried out at home.

In the included studies, the monitoring of activities was carried out through of daily logs [25], parental supervision [25, 32] home visits [26-28, 30, 31, 37], telephone calls $[29,35,38]$, or closely monitored by the physiotherapist-in-charge [33, 36, 39]. Only one study did not carry out monitoring of adherence during the intervention phase [33]. Three studies used the Constraint-Induced Movement Therapy (CIMT) to improve unilateral and bilateral motor performance and daily functions in individuals with Cerebral Palsy (CP) [25, 32] and Stroke [30]. Four included studies used exercise programmes based on conventional rehabilitation, involving strength training, cardiorespiratory fitness training, balance and walking training $[26-28,33,36]$. One of these studies provided the exercises through DVDs [28]. The neurological population that performed these conventional rehabilitation programs varied among individuals with Stroke [27, 28], Parkinson's Disease [26] and Traumatic Brain Injury [33].

Others three studies used virtual reality rehabilitation programme to improve arm function $[29,37]$ and balance [39]. One study utilized a step training mat, connected wirelessly to the television by a console, to improve balance, stepping, cognition and functional performance in people with Multiple Sclerosis [35]. Transcutaneous electrical nerve stimulation (TENS) was used in combination with task-related training in two included studies [31,34], with the aim of treatment on spasticity [31] and muscle strength [34] in Stroke patients. One study used a home-based program of music therapy associate with resistance exercise to investigate the effect of additional patterned sensory enhancement on gross motor capacity, functional strength, daily mobility and self-care functions, and walking speed in children with CP [38]. 


\begin{tabular}{|c|c|c|c|c|c|c|c|}
\hline 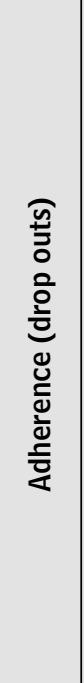 & 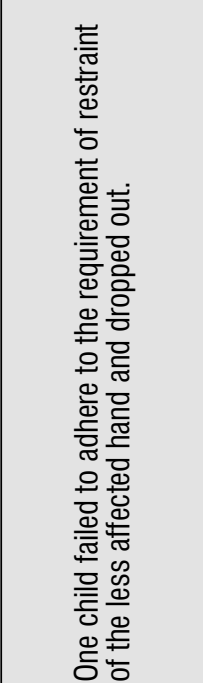 & 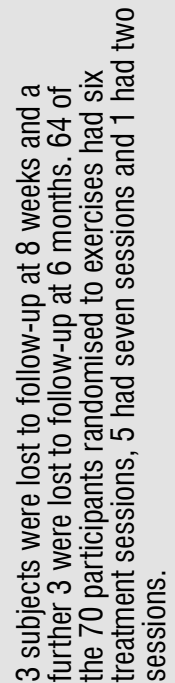 & 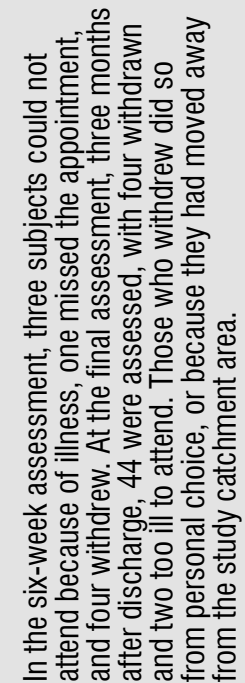 & 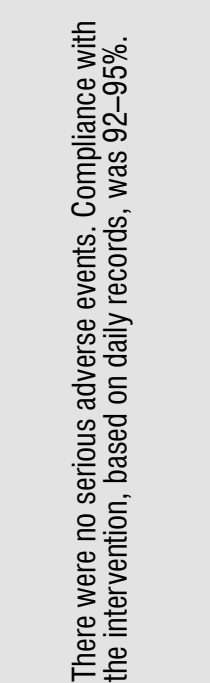 & 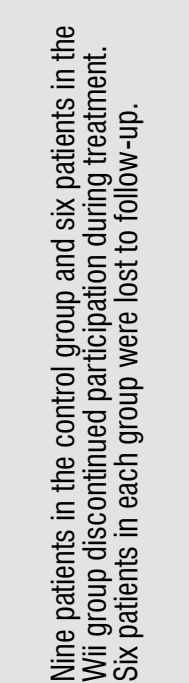 & 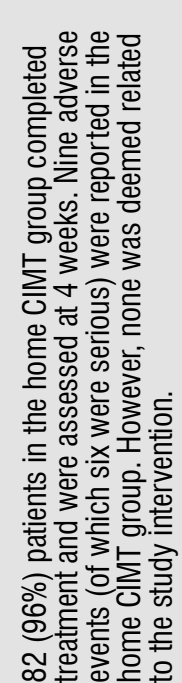 & 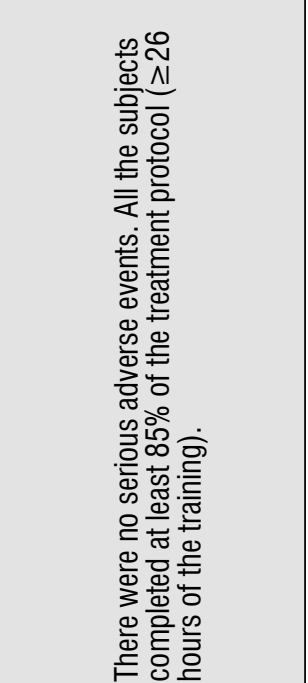 \\
\hline 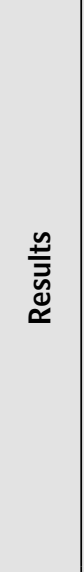 & 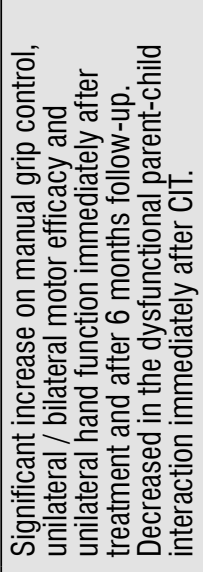 & 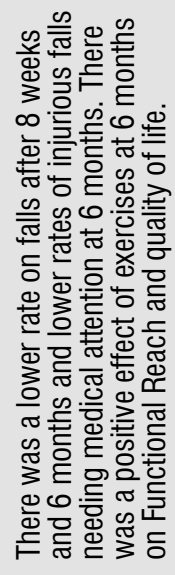 & 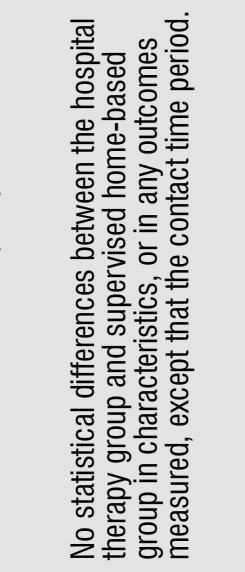 & 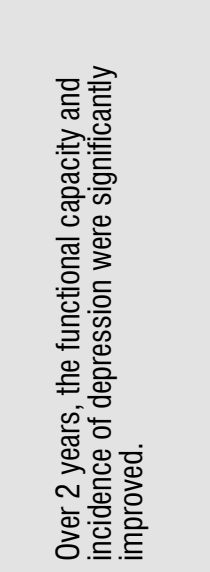 & 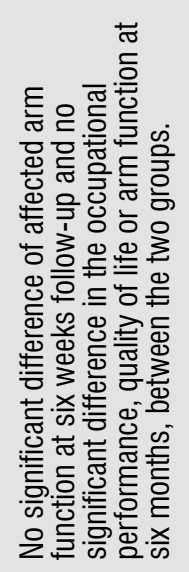 & 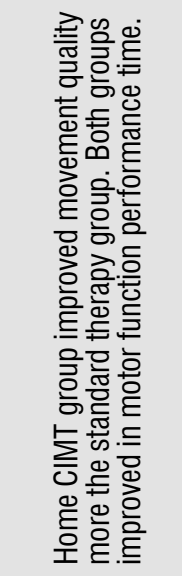 & 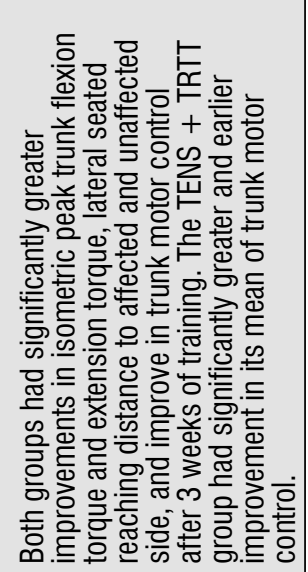 \\
\hline$\stackrel{\mathscr{I}}{\underline{E}}$ & 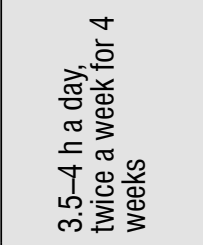 & 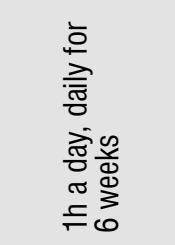 & 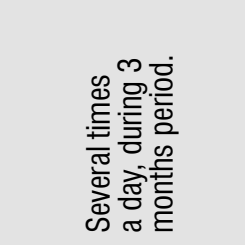 & 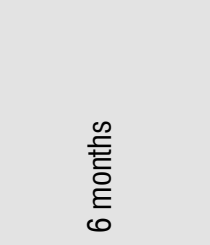 & 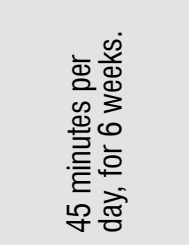 & 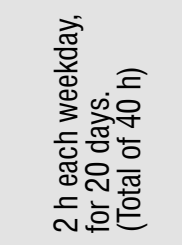 & 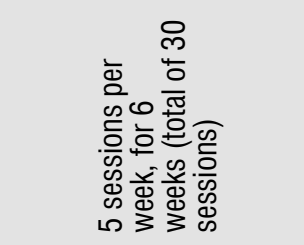 \\
\hline 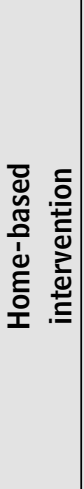 & 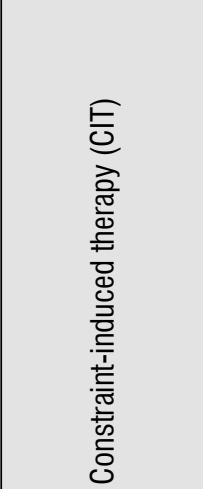 & 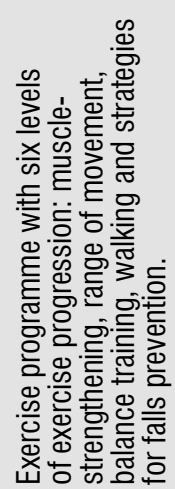 & 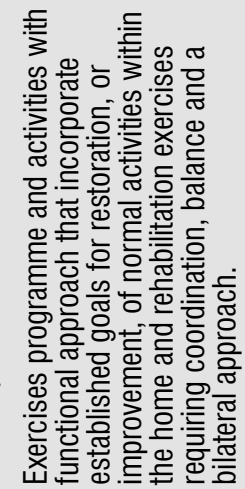 & 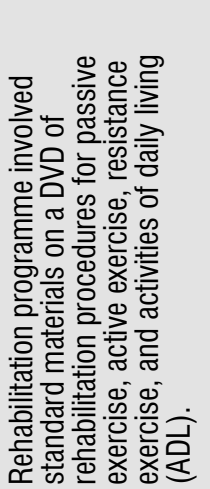 & 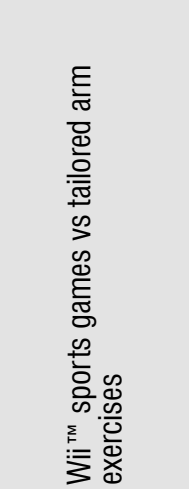 & 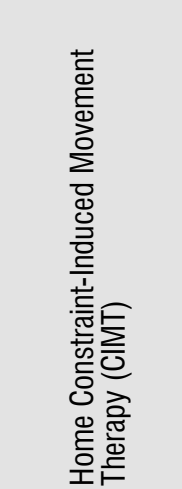 & 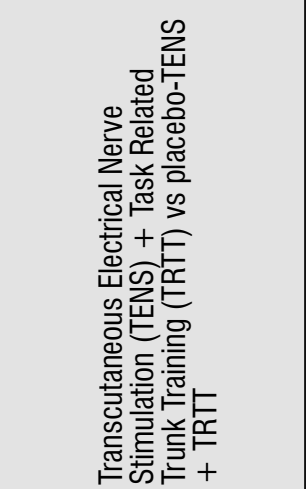 \\
\hline 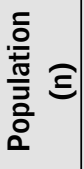 & 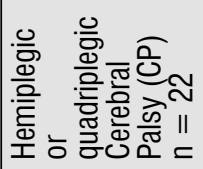 & 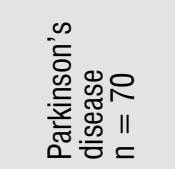 & 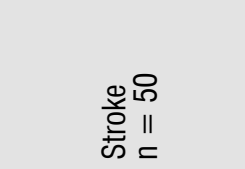 & 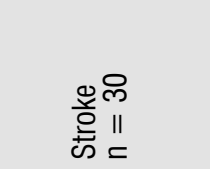 & 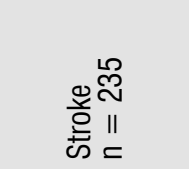 & 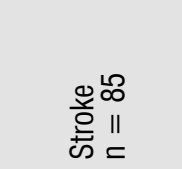 & 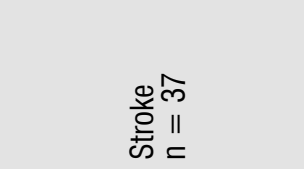 \\
\hline 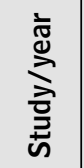 & 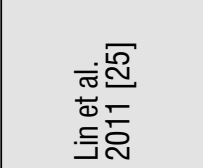 & 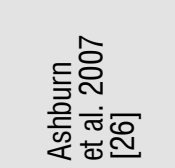 & 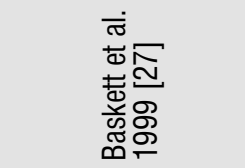 & 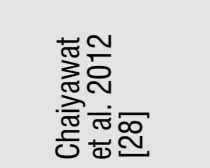 & 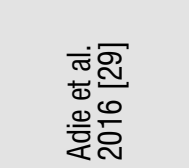 & 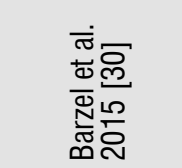 & 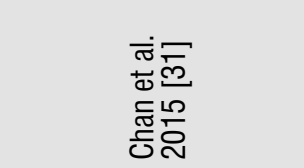 \\
\hline
\end{tabular}




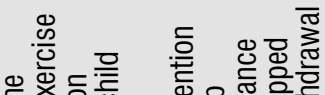

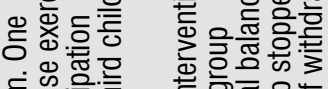

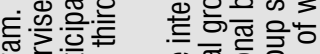

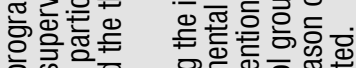

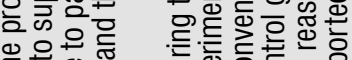

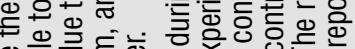

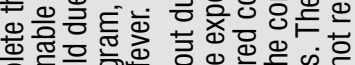

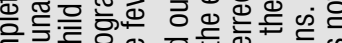
हो

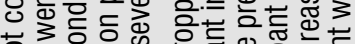
믄 음

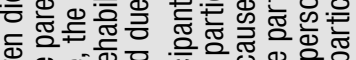
은 흘

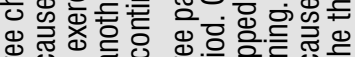

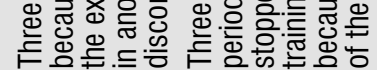

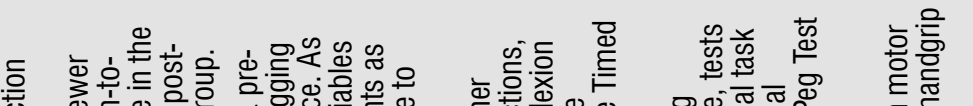

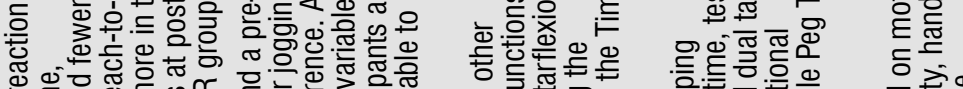

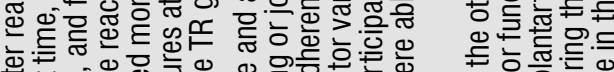

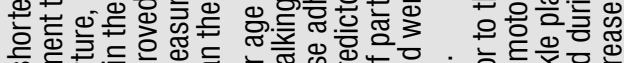

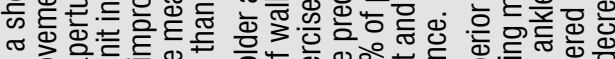

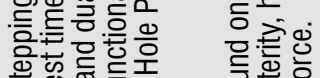

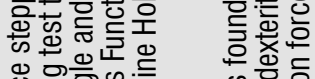

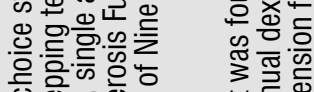

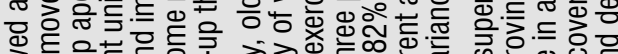

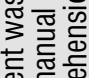

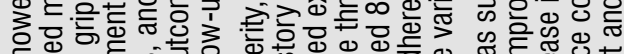

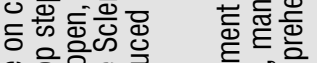

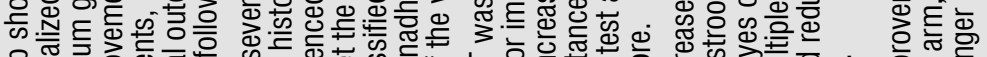

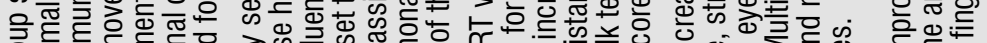

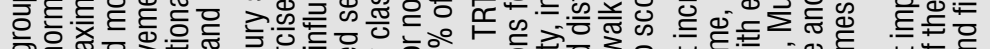

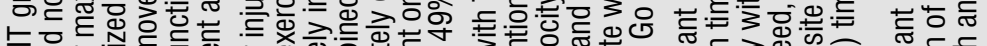

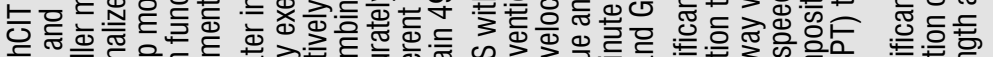
에

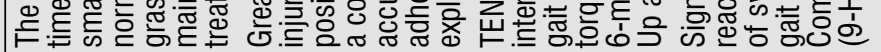

क号它离

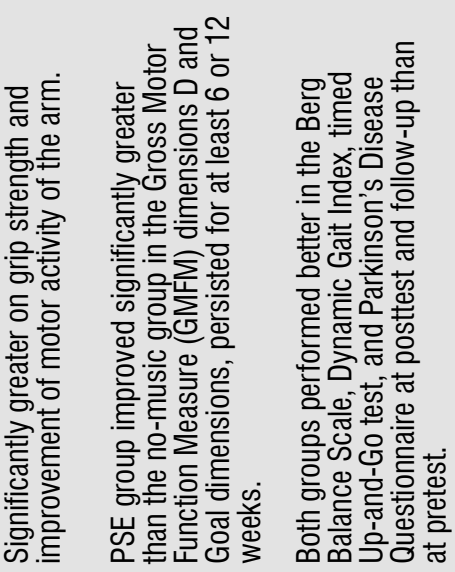

\begin{tabular}{|c|c|c|c|c|c|c|c|c|}
\hline$\stackrel{\mathscr{E}}{\underline{E}}$ & 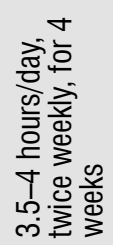 & 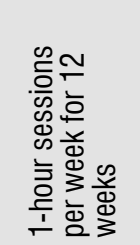 & 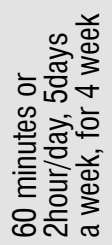 & 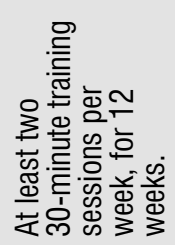 & 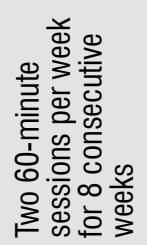 & 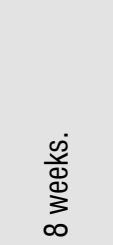 & 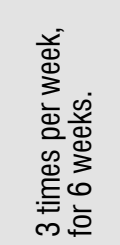 & 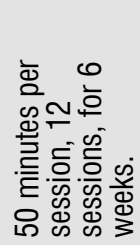 \\
\hline 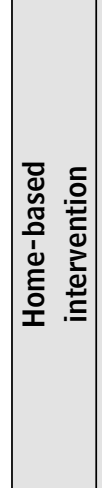 & 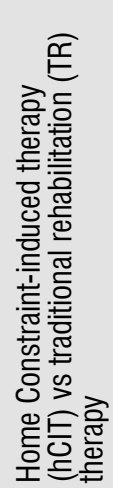 & 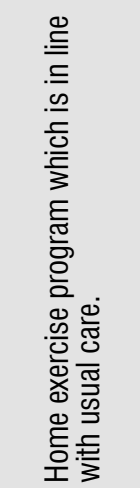 & 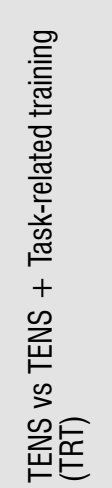 & 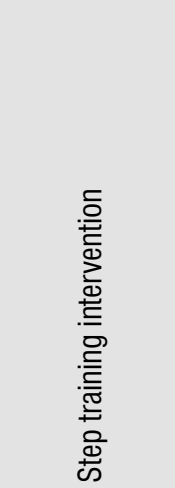 & 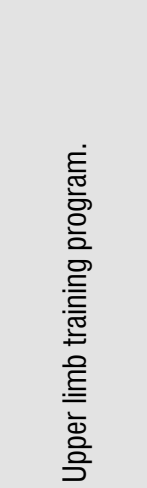 & 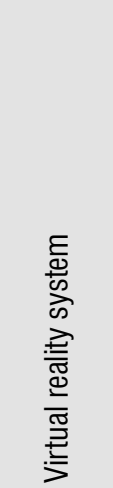 & 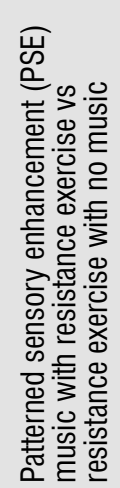 & 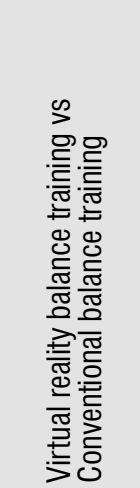 \\
\hline$\frac{\overline{0}}{\frac{0}{\bar{t}}}$ & 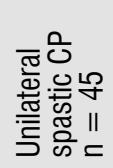 & 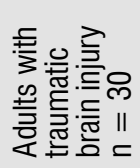 & 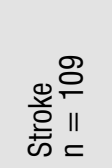 & 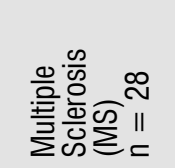 & 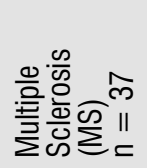 & 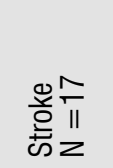 & 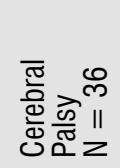 & 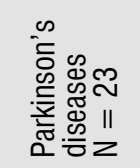 \\
\hline 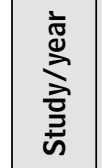 & 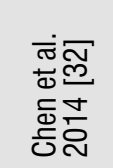 & 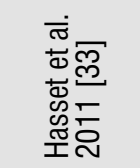 & 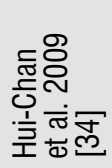 & 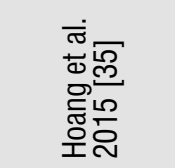 & 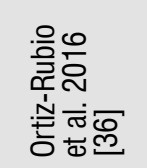 & 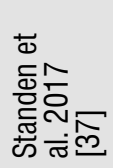 & 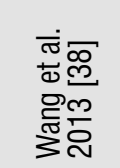 & 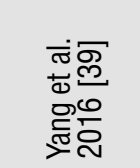 \\
\hline
\end{tabular}


Effects of home-based interventions

Pooling of data from included studies was confounded by heterogeneity amongst the trials mentioned above and all included studies were critiqued qualitatively rather than attempting a meta-analysis.

All studies reported changes in motor recovery level in the home-based physiotherapy programmes ( $\mathrm{n}=804$ participants) (Table 2). Two studies reported no significant difference in the experimental group compared to the control group. However, both groups had interventions performed at home and obtained improvement was seen from baseline [27, 29]. Three studies showed a significant improvement in functional activity in the intervention group in the post-intervention evaluation, remaining after 6 months [25, 26] and 2 years of follow-up [28]. Five studies showed a significant improvement in the control and muscle strength of trunk [31] and upper $\operatorname{limb}[25,32,36,37]$. Others five studies $[26,33-35,39]$ showed that a home-based physiotherapy programme improved the balance, walking, and falls prevention.

Only one study [29] reported data on costeffectiveness, showing no difference in mean qualityadjusted life years between the two groups. However, the $\mathrm{Wii}^{\mathrm{TM}}$ used to virtual therapy rehabilitation was more expensive than arm exercises.

\section{Adherence to home-based intervention}

Table 2 summarizes the dropouts and barriers to treatment adherence for each included study. In three studies [25, 38, 39], lack of adherence was reported because of the treatment performed. In two of these three studies [38, 39], the child preferred to undertake another rehabilitation program. In the third study [25], a child failed to meet the least affected hand restriction requirement at the CIMT and drop out. Seven studies [27, 30, 32, 35, 37-39] had dropout due to adverse events, health problems or either family matters. However, none was deemed related to the study intervention. Three studies [26, 29, 32] showed loss of follow-up, with no specific reasons. One study [29] did not report the reason for loss of adherence to treatment. In four studies [28,31,33,36], all the patients completed the treatment and no adverse effects were reported by any patient.
Despite the dropout reported in the studies, there was good adherence: of the 804 participants, 50 were lost, the majority were not due to the use of the homebased intervention. Of the 11 studies [25-27, 29, 30, $32,34,35,37-39]$ that presented dropouts, seven [26, $27,29,30,34,38,39]$ used intention-to-treat analysis.

\section{Discussion}

This systematic review applied a multipronged and broad approach to assimilate published literature to provide the wider picture of currently available evidence, by including randomized controlled clinical trials. Were summarised the results from 15 moderate to high quality studies. The home-based physiotherapy programmes evaluated in the included studies showed marked heterogeneity in terms of characteristics, type and mode of delivery of the interventions, treatment and control protocols and length of follow-up.

Moderate to high quality evidence supports the positive impact of home-based intervention for individuals with neurological conditions, such as CP [25, 32, 38], Parkinson's Diseases [26, 39], Stroke [27-31, 34, 37], Traumatic Brain Injury [33] and Multiple Sclerosis [35, 36]. This systematic review found evidence that changes in activity level, improvement in the control and muscle strength, balance and walking can be found in patients with neurological conditions who perform rehabilitation program at home. There was no evidence for the cost-effectiveness of these programmes and for the best type/mode/intensity (frequency and duration) of interventions or superiority of one intervention over another.

Poor caregiver support or activity and the child's preference for the type of treatment were the main reasons for barriers to treatment adherence of studies involving children [25, 32, 38]. In the most studies involving adults with neurological conditions, health problems, discontinuation for personal reasons, and low in-follow up adherence were barriers to treatment adherence [26-31, 33-37, 39].

Rehabilitation is a complex intervention, defined as "complex" where the active ingredient in the intervention is not easily identifiable. There are many challenges in in choosing the type of intervention. Firstly, individuals with neurological diseases can present with diverse clinical presentations and with varying levels of disability, requiring an individualized 
approach. The perspectives of patients (and/or caregivers), is often neglected and needs to be incorporated in any treatment programmes including home-based intervention, especially in interventions performed on children. Despite the possible dropouts and withdrawals during the execution of a homebased programme, often the reason for giving up is not related to the intervention, but due to family or health problems, as found in our study.

Limitations in the methodology and the completeness of this review cannot be ruled out. For the reason that this systematic revision attempts to synthesize evidence of interventions that are incorporated in the course of the actual clinical practice, we chose not to analyze the use of therapies based on Information Technology and Communication (ICT), such as telereabilitation, inserting only concrete rehabilitation programs, which are considered viable, requiring no knowledge or access to technology or equipment not known in outpatient therapy.

\section{Conclusion}

New models of rehabilitative care such as homebased programmes can be an alternative efficient method to deliver rehabilitation, showing to be beneficial in improving different aspects of activities, and participation. However, the findings from existing studies are inconclusive, and assimilation of data was difficult due to the diversity of contents of Homebased programmes. Future studies are needed for future research into optimal intensity, frequency and cost-effectiveness of thome-based intervention over short and long term.

\section{References}

1. Carmeli E. Physical therapy for neurological conditions in geriatric populations. Front Public Health. 2017;5:333.

2. Barnes MP. Principles of neurological rehabilitation. J Neurol Neurosurg Psychiatry. 2003;74(Suppl 4):iv3-7.

3. Ward CD, Phillips M, Smith A, Moran M. Multidisciplinary approaches in progressive neurological disease: can we do better? J Neurol Neurosurg Psychiatry. 2003;74 (Suppl 4):iv8-12.
4. Jack K, McLean SM, Moffett JK, Gardiner E. Barriers to treatment adherence in physiotherapy outpatient clinics: a systematic review. Man Ther. 2010,15(3):220-8.

5. Turner-Stokes L. Cost-efficiency of longer-stay rehabilitation programmes: can they provide value for money? Brain Inj. 2007;21(10):1015-21.

6. Turner-Stokes L. The evidence for cost-effectiveness of rehabilitation following acquired brain injury. Clin Med (Lond). 2004;4(1):10-2.

7. Paleg G, Livingstone R. Systematic review and clinical recommendations for dosage of supported homebased standing programs for adults with stroke, spinal cord injury and other neurological conditions. BMC Musculoskelet Disord. 2015;16:358.

8. Rae-Grant AD, Turner AP, Sloan A, Miller D, Hunziker J, Haselkorn JK. Self-management in neurological disorders: Systematic review of the literature and potential interventions in multiple sclerosis care. J Rehabil Res Dev. 2011;48(9):1087-100.

9. Beckers LW, Schnacker ML, Janssen-Potten YJ, Kleijnen J, Steenbergen B. Feasibility and effect of homebased therapy programmes for children with cerebral palsy: a protocol for a systematic review. BMJ Open. 2017;7(2):e013687.

10. Oddy, M, Silva Ramos, S. Cost effective ways of facilitating home based rehabilitation and support. NeuroRehabilitation. 2013;32(4):781-90.

11. Novak I , Berry J . Home program intervention effectiveness evidence. Phys Occup Ther Pediatr. 2014;34(4):384-9.

12. Amatya B, Galea MP, Kesselring J, Khan F. Effectiveness of telerehabilitation interventions in persons with multiple sclerosis: a systematic review. Mult Scler Relat Disord. 2015;4(4):358-69.

13. Jamwal R, Callaway L, Ackerl J, Farnworth L, Winkler D. Electronic assistive technology used by people with acquired brain injury in shared supported accommodation: implications for occupational therapy. Br J Occup Ther. 2017;80(2):89-98. 
14. Jamwal R, Callaway L, Winkler D, Farnworth L, Tate R. Evaluating the use of smart home technology by people with brain impairment: protocol for a single-case experimental design. JMIR Res Protoc. 2018;7(11):e10451.

15. Chen J, Jin W, Dong WS, Jin Y, Qiao FL, Zhou YF, et al. Effects of home-based telesupervising rehabilitation on physical function for stroke survivors with hemiplegia: a randomized controlled trial. Am J Phys Med Rehab. 2016;96(3):152-60.

16. Hailey D, Roine R, Ohinmaa A, Dennett L. The status of telerehabilitation in neurological applications. J Telemed Telecare. 2013;19(6):307-10.

17. Peretti A, Amenta F, Tayebati SK, Nittari G, Mahdi SS. Telerehabilitation: review of the state-of-the-art and areas of application. JMIR Rehabil Assist Technol. 2017;4(2):e7.

18. Hailey D, Roine R, Ohinmaa A, Dennett L. Evidence of benefit from telerehabilitation in routine care: a systematic review. J Telemed Telecare. 2011;17(6):281-7.

19. Jimison H, Gorman P, Woods S, Nygren P, Walker M, Norris $S$, et al. Barriers and drivers of health information technology use for the elderly, chronically ill, and underserved. Rockville, MD: Agency for Healthcare Research and Quality; 2008.

20. Blaschke CM, Freddolino PP, Mullen EE. Ageing and technology: a review of the research literature. Br J Soc Work. 2009;39(4):641-56.

21. Liberati A, Altman DG, Tetzlaff J, Mulrow C, Gøtzsche PC, Ioannidis JPA, et al. The PRISMA statement for reporting systematic reviews and meta-analyses of studies that evaluate health care interventions: explanation and elaboration. PLoS Med. 2009;6(7):e1000100.

22. Moher D, Liberati A, Tetzlaff J, Altman DG; PRISMA Group. Preferred reporting items for systematic reviews and meta-analyses: the PRISMA Statement. BMJ. 2009;339:b2535.

23. Shiwa SR, Costa LO, Moser AD, Aguiar IC, Oliveira LV. PEDro: the physiotherapy evidence database. Fisioter Mov. 2011;24(3):523-33.
24. Carvalho APV, Silva V, Grande AJ. Avaliação do risco de viés de ensaios clínicos randomizados pela ferramenta de colaboração Cochrane. Diagn Tratamento. 2013;18(1):38-44.

25. Lin KC, Wang TN, Wu CY, Chen CL, Chang KC, Lin YC, et al. Effects of home-based constraint-induced therapy versus dose-matched control intervention on functional outcomes and caregiver well-being in children with cerebral palsy. Res Dev Disabil. 2011;32(5):1483-91.

26. Ashburn A, Fazakarley L, Ballinger C, Pickering R, McLellan LD, Fitton C. A randomised controlled trial of a home-based exercise programme to reduce risk of falling among people with Parkinson's disease. J Neurol Neurosurg Psychiatry. 2007;78(7):678-84.

27. Baskett JJ, Broad JB, Reekie G, Hocking C, Green G. Shared responsibility for ongoing rehabilitation: a new approach to home-based therapy after stroke. Clin Rehabil. 1999;13(1):23-33.

28. Chaiyawat P, Kulkantrakorn K, Sritipsukho P. Effectiveness of home rehabilitation for ischemic stroke. Neurol Int. 2009;1(1):e10.

29. Adie K, Schofield C, Berrow M, Wingham J, Humfryes J, Pritchard C, et al. Does the use of Nintendo Wii Sports ${ }^{\mathrm{TM}}$ improve arm function? Trial of $\mathrm{Wii}^{\mathrm{TM}}$ in stroke: a randomized controlled trial and economics analysis. Clin Rehabil. 2017;31(2):173-85.

30. Barzel A, Liepert J, Haevernick K, Eisele M, Ketels G, Rijntjes $\mathrm{M}$, et al. Comparison of two types of ConstraintInduced Movement Therapy in chronic stroke patients: a pilot study. Restor Neurol Neurosci. 2009;27(6):673-80.

31. Chan BK, Ng SS, Ng GY. A home-based program of transcutaneous electrical nerve stimulation and taskrelated trunk training improves trunk control in patients with stroke a randomized controlled clinical trial. Neurorehabil Neural Repair. 2015;29(1):70-9.

32. Chen HC, Chen CL, Kang LJ, Wu CY, Chen FC, Hong WH. Improvement of upper extremity motor control and function after home-based constraint induced therapy in children with unilateral cerebral palsy: immediate and long-term effects. Arch Phys Med Rehabil. 2014;95(8):1423-32. 
33. Hassett LM, Tate RL, Moseley AM, Gillett LE. Injury severity, age and pre-injury exercise history predict adherence to a home-based exercise programme in adults with traumatic brain injury. Brain Inj. 2011;25(7-8):698-706.

34. Hui-Chan C, Ng SS, Mak MK. Effectiveness of a homebased rehabilitation programme on lower limb functions after stroke. Hong Kong Med J. 2009;15(3 Suppl 4):42-6.

35. Hoang P, Schoene D, Gandevia S, Smith S, Lord SR. Effects of a home-based step training programme on balance, stepping, cognition and functional performance in people with multiple sclerosis-a randomized controlled trial. Mult Scler. 2016;22(1):94-103.

36. Ortiz-Rubio A, Cabrera-Martos I, Rodríguez-Torres J, Fajardo-Contreras W, Díaz-Pelegrina A, Valenza MC. Effects of a home-based upper limb training program in patients with multiple sclerosis: a randomized controlled trial. Arch Phys Med Rehabil. 2016;97(12):2027-33.

37. Standen PJ, Threapleton K, Richardson A, Connell L, Brown DJ, Battersby S, et al. A low cost virtual reality system for home based rehabilitation of the arm following stroke: a randomised controlled feasibility trial. Clin Rehabil. 2017;31(3):340-50.
38. Wang TH, Peng YC, Chen YL, Lu TW, Liao HF, Tang $\mathrm{PF}$, et al. A home-based program using patterned sensory enhancement improves resistance exercise effects for children with cerebral palsy: a randomized controlled trial. Neurorehabil Neural Repair. 2013;27(8):684-94.

39. Yang WC, Wang HK, Wu RM, Lo CS, Lin KH. Homebased virtual reality balance training and conventional balance training in Parkinson's disease: a randomized controlled trial. J Formos Med Assoc. 2016;115(9):734-43.

40. Malavolta EA, Demange MK, Gobbi RG, Imamura M, Fregni F. Randomized controlled clinical trials in orthopedics. Rev Bras Ortop. 2011;46(4):452-9.

Received in 12/06/2018 Recebido em 06/12/2018 Recibido en 06/12/2018

Approved in 03/07/2019 Aprovado em 07/03/2019 Aprobado en 07/03/2019 